\title{
Interferon Free Therapy with and Without Ribavirin for Genotype 1 HCV Cirrhotic Patients in the Real World Experience
}

\author{
Dorota Zarebska-Michaluk ${ }^{1,{ }^{*}}$, Jerzy Jaroszewicz ${ }^{2}$, Ewa Janczewska ${ }^{3}$, Hanna Berak ${ }^{4}$, Andrzej Horban ${ }^{4}$, Marek Sitko ${ }^{5}$, Aleksander Garlicki ${ }^{5}$, Beata \\ Dobracka $^{6}$, Agnieszka Czauż-Andrzejuk ${ }^{7}$, Dorota Dybowska ${ }^{8}$, Waldemar Halota ${ }^{8}$, Małgorzata Pawłowska ${ }^{8}$, Magdalena Tudrujek-Zdunek ${ }^{9}$, Krzysztof \\ Tomasiewicz $^{9}$, Włodzimierz Mazur ${ }^{10}$, Zbigniew Deroń ${ }^{11}$, Teresa Belica-Wdowik ${ }^{12}$, Barbara Baka-Ćwierz ${ }^{12}$, Iwona Buczyńska ${ }^{13}$, Krzysztof Simon ${ }^{13}$, Anna \\ Piekarska ${ }^{14}$, Jolanta Białkowska-Warzecha ${ }^{15}$, Beata Lorenc ${ }^{16}$, Rafał Krygier ${ }^{17}$, Agnieszka Staniaszek ${ }^{18}$, Jakub Klapaczyński ${ }^{18}$, Jolanta Citko ${ }^{19}$, Łukasz \\ Socha ${ }^{20}$, Marta Wawrzynowicz-Syczewska ${ }^{20}$, tukasz Laurans $^{20,21}$ and Robert Flisiak ${ }^{7}$ \\ I Department of Infectious Disease, Voivodeship Hospital, Jan Kochanowski University, Kielce, Poland

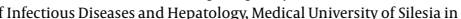 \\ Medical University of Silesia, School of Public Health in Bytom, Department of Basic Medical Sciences, Bytom; ID Clinic, Hepatology Outpatient Department, Mystowice, Poland \\ ${ }^{4}$ Hospital for Infectious Diseases, Warsaw Medical University, Warszawa, Poland \\ 5 Department of Infectious and Tropical Diseases, Collegium Medicum, Jagiellonian University, Kraków, Poland \\ ${ }^{6}$ Medical Center, MEDFIX, Wroctaw, Poland \\ ' Department of Infectious Diseases and Hepatology, Medical University of Białystok, Białystok, Poland \\ ${ }^{8}$ Department of Infectious Diseases and Hepatology, Faculty of Medicine, Nicolaus Copernicus University, Bydgoszcz, Poland \\ ${ }^{2}$ Department of Infectious Diseases, Medical University of Lublin, Lublin, Poland \\ Clinical Department of Infectious Diseases, Medical University of Silesia, Chorzów, Poland \\ Ward of Infectious Diseases and Hepatology, Biegański Regional Specialist Hospital, Łódź, Poland \\ ${ }^{13}$ Department of Infectious Diseases and Hepatology, Wroclaw University of Medicine, Wroctaw, Poland \\ ${ }^{14}$ Department of Infectious Diseases and Hepatology, Medical University of Lodz, Eódż, Poland \\ ${ }^{15}$ Department of Infectious and Liver Diseases, Medical University of Łódz, Lódź, Poland \\ ${ }^{17}$ Department of Infectious Diseases, Pomeranian Center of Infectious Diseases, Medical University of Gdańsk, Gdańsk, Poland \\ ${ }^{17} \mathrm{NZOZ} \mathrm{Gemini,} \mathrm{Infectious} \mathrm{Diseases} \mathrm{and} \mathrm{Hepatology} \mathrm{Outpatient} \mathrm{Clinic,} \mathrm{Żychlin,} \mathrm{Poland}$ \\ ${ }_{18}^{18}$ Department of Internal Medicine and Hepatology, Central Clinical Hospital of Internal Affairs and Administration, Warszawa, Poland \\ 19 Regional Hospital, Olsztyn, Poland \\ Department of Infectious Diseases, Hepatology and Liver Transplantation, Pomeranian Medical University, Szczecin, Poland \\ ${ }^{21}$ Outpatient Department, Multidisciplinary Regional Hospital, Gorzów, Poland \\ "Corresponding author: Department of Infectious Diseases, Voivodship Hospital Kielce, 25-640 Kielce, Poland Ul., Radiowa 7, Kielce, Poland. Tel: +48-662441465, Fax: +48-413682262, Email: dorota1010@tlen.pl
}

Received 2018 June 12; Revised 2018 July 08; Accepted 2018 July 24.

\begin{abstract}
Background: In the interferon era, patients with HCV-related cirrhosis were considered hard to treat due to contraindications to therapy, safety issues, and poor response. Objectives: We investigated interferon-free regimens in cirrhotic patients in real-world practice.

Methods: We analyzed data of HCV infected patients with liver cirrhosis conducted in 22 Polish hepatology centers. They were assigned to a treatment schedule based on physician decision. Data were collected retrospectively by an online questionnaire.

Results: In total, 1113 patients infected with genotype $1 \mathrm{HCV}$ were enrolled to the analysis, $96.6 \%$ presented GT1b infection. A total of $56 \%$ were treatment-experienced, mostly with PegIFN + RBV, $77.2 \%$ of group presented comorbidities with the most frequent hypertension and diabetes,73.2\% patients were treated with concomitant medications, and 31\% of cohort was assigned to RBV-free regimen, majority of them to OBV/PTV/r+ DSV. Overall, $94.7 \%$ patients achieved the sustained virological response in intent-to-treat analysis, with comparable rate for RBV-free and RBV-containing options ( $94.2 \%$ vs. $94.9 \%)$. Treatment course was more often modified in RBV-containing group, whereas rate of discontinuation was the same for both cohorts. Adverse events were observed in $41 \%$ with the most common weakness/fatigue; more frequently in RBV-containing regimens ( $43 \%$ vs. $36.6 \%$ ). Serious adverse events were reported in $4.1 \%$ patients. A total of 16 deaths not related to study drugs were documented, mostly in RBV-containing group.

Conclusions: We confirmed effectiveness of the interferon-free regimens without ribavirin in real-world cohort of cirrhotic patients with chronic HCV infection genotype 1. Therapy was well tolerated with infrequent adverse events.
\end{abstract}

Keywords: Hepatitis C Virus, Genotype 1, Liver Cirrhosis

\section{Background}

The hepatitis $\mathrm{C}$ virus (HCV) infection is a global health issue affecting approximately 71 million individuals all over the world. Untreated chronic hepatitis $C$ is a leading cause of cirrhosis and end-stage liver disease (1). The most prevalent worldwide is genotype 1 (GT1), which accounts for $46 \%-60 \%$ infections. In Europe, genotype 1 is responsible for the majority of chronic hepatitis $C$ cases. Of the GT1 infections, subtype $1 \mathrm{~b}$ is the most common, which accounts for about $50 \%$ of all HCV infections in Western Europe and much higher percentages in Eastern European countries, including Poland $(2,3)$. In the interferon era, patients with HCV-related cirrhosis infected genotype 1 were considered difficult to treat due to contraindications to therapy, safety issues, and poor response (4-7).

Introduction of interferon-free regimens containing a combination of direct acting antivirals (DAA) and possible addition of ribavirin (RBV) improved treatment efficacy in GT1 infected patients up to $100 \%$, even in hard to treat population of cirrhotics. From 2015, four IFN-free regimens were recommended by EASL for GT 1 patients with compensated liver cirrhosis: OBV/PTV/r + DSV + RBV, SOF/LDV $\pm \mathrm{RBV}, \mathrm{SOF}+$ $\mathrm{SMV} \pm \mathrm{RBV}$ and $\mathrm{SOF}+\mathrm{DCV} \pm \mathrm{RBV}$, and two options: $\mathrm{SOF} / \mathrm{LDV}$ 
+ RBV and SOF + DCV + RBV for decompensated cirrhotics (8, 9).

\section{Objectives}

In the present analysis we have investigated interferonfree regimens in cirrhotic patients infected with GT1 in realworld practice with particular reference to efficacy and safety of ribavirin-free options.

\section{Methods}

The analysis is a part of EpiTer-2, real-world, investigator-initiated, manufacturer-independent, observational study, which included 22 Polish centers treating $\mathrm{HCV}$ infected patients.

A total of 2879 adults with chronic hepatitis C who started antiviral therapy after July 1, 2015 and completed it before December 31, 2016, with the efficacy evaluation available before June 30, 2017, were enrolled in the study. In the study cohort, 1254 patients were diagnosed as cirrhotic, of which 1113 were infected with genotype 1 . The selection of the current therapy was made by treating physicians. Patients were treated according to the reimbursed therapeutic program of the National Health Fund and in line with recommendations of the Polish Group of Experts for HCV. The efficacy end point was the sustained virological response (SVR) described as undetectable HCV RNA at least 12 weeks after the end of treatment. Data concerning baseline characteristics and treatment course, including efficacy and safety, were collected retrospectively and submitted using the online questionnaire administered by Tiba sp. z o.o. The study was supported by the Polish Association of Epidemiologists and Infectiologists. In the beginning of the analyzed period, GT $1 \mathrm{~b}$ cirrhotic patients were treated with ribavirin. However after an update of the Summary of Product Characteristics in April 2016 following TURQUOISE-III study results publication, cirrhotics became allowed to be treated without RBV (16). In Poland, the combination of SOF and DCV was not reimbursed, thus, this option was available for very few patients and was therefore not included in the current analysis.

Statistical analyses. The results are expressed as mean \pm standard deviation (SD) or No. (\%). P values of $<0.05$ were considered to be statistically significant. The significance of difference was calculated by use of Chi-square or Fischer's exact test and where appropriate by use of GraphPad Prism 5.1 (GraphPad Software, Inc., La Jolla, CA).

\section{Results}

In total 1113 cirrhotic patients infected with genotype 1 $\mathrm{HCV}$ were included in the analysis. Males were accounted for $48 \%$ with a mean age of $58.9 \pm 11.7$ years; females were older than males. Over $70 \%$ of patients suffered from comorbidities, of which hypertension and diabetes were the most common. Almost three-fourths were treated with concomitant medications and 31\% of the entire cohort was assigned to the RBV-free regimens, whereas remaining 69\% received RBV-containing treatment. Details of baseline characteristics of the study cohort are presented in Table 1.

The vast majority of the analyzed population was infected with genotype $1 \mathrm{~b}$ with $98 \%$ in the RBV-free and $96 \%$ in RBV-containing groups, respectively. The most frequent method of the liver fibrosis assessment supporting diagnosis of cirrhosis was transient elastography (TE) performed in almost two thirds of the cohort, followed by liver biopsy and shear-wave elastography (SWE); only single patients were diagnosed based on acoustic radiation force impulse (ARFI) (10).

Hepatic decompensation at baseline manifested as an ascites and encephalopathy was observed in $4.1 \%$ and $2.5 \%$ of patients, respectively, more often in RBV-containing (4.9\% and $3.1 \%$ ) than RBV-free group (2.3\% and $1.2 \%$ ). The majority of patients (86.7\%) at baseline were classified as compensated (class A in Child-Pugh score) with comparable rate for both subpopulations, however, a history of hepatic decompensation in form of ascites and encephalopathy was more often reported in RBV-containing group (P $=0.003$ ) as shown in Table 2 . A total of $56 \%$ of the study cohort was treatment-experienced with null response as the most frequent type of non-response. Most of them (58\%) were treated previously with pegylated interferon alfa (PegIFN) and RBV, and 31.5\% received triple therapy with telaprevir, boceprevir, simeprevir, or sofosbuvir combined with PegIFN and RBV. The most frequent option without RBV was 12 weeks of ombitasvir/paritaprevir/ritonavir + dasabuvir (OBV/PTV/r + DSV) accounting for 63\% of therapies in this population. The frequency of application of other treatment options are presented in Table 3. Overall, $94.7 \%$ of patients achieved the sustained virological response in intent-to-treat analysis, with comparable rate for RBV-free and RBV-containing options (94.2\% vs. 94.9\%, P = 0.61). Treatment efficacy for the most common therapeutic options with OBV/PTV/r + DSV for 12 weeks was 96\% regardless RBV administration. In RBV-free regimens, SVR rate for 12-week options was higher than 24-week ones ( $96 \%$ vs. $89 \%, \mathrm{P}=0.01$ ), whereas in RBV-containing schedules SVR rate was $95 \%$ irrespective of the treatment duration (Table 4). Treatment course was more often modified in the RBV- 


\begin{tabular}{|c|c|c|c|}
\hline Parameter & All, $N=1113$ & RBV-Free $N=344$ & RBV-Containing $N=769$ \\
\hline Gender, females/males & $574(51.6) / 539(48.4)$ & $192(55.8) / 152(44.2)$ & $382(49.7) / 387(50.3)$ \\
\hline Age $(y)$, mean $+S D(\min -\max )$ & $58.9 \pm 11.7(21-91)$ & $59.9 \pm 12.2(25-90)$ & $58.5 \pm 11.6(21-91)$ \\
\hline Females & $62.3 \pm 10.8(25-91)$ & $62.9 \pm 11.6(25-90)$ & $62 \pm 10.4(26-91)$ \\
\hline Males & $55.3 \pm 11.7(21-86)$ & $56.1 \pm 11.9(29-84)$ & $54.9 \pm 11.6(21-86)$ \\
\hline BMI, mean + SD $(\min -\max )$ & $27.3 \pm 4.5(13.4-49.4)$ & $27.2 \pm 4.1(15.6-42.6)$ & $27.4 \pm 4.6(13.4-49.4)$ \\
\hline \multicolumn{4}{|l|}{ Comorbidities } \\
\hline Any comorbidity & $859(77.2)$ & $268(77.9)$ & $591(76.9)$ \\
\hline Hypertension & $545(49)$ & $173(50.3)$ & $372(48.4)$ \\
\hline Diabetes & $245(22)$ & $69(20)$ & $176(22.9)$ \\
\hline Renal disease & $43(3.9)$ & $19(5.5)$ & $24(3.1)$ \\
\hline Autoimmune diseases & $27(2.4)$ & $10(2.9)$ & $17(2.2)$ \\
\hline Non-HCC tumors & $19(1.7)$ & $6(1.7)$ & $13(1.7)$ \\
\hline Other & $584(52.5)$ & $167(48.5)$ & $417(54.2)$ \\
\hline Concomitant medications & $815(73.2)$ & $247(71.8)$ & $568(73.8)$ \\
\hline ALT IU/L & $95.7 \pm 66.2$ & $95.1 \pm 65.5$ & $96 \pm 66.6$ \\
\hline Bilirubin mg/dL & $1.19 \pm 0.96$ & $1.14 \pm 1.06$ & $1.22 \pm 0.9$ \\
\hline Albumin g/dL & $3.8 \pm 0.56$ & $3.8 \pm 0.53$ & $3.8 \pm 0.58$ \\
\hline Creatinine mg/dL & $0.84 \pm 0.58$ & $0.92 \pm 0.92$ & $0.8 \pm 0.32$ \\
\hline Hemoglobin g/dL & $14.1 \pm 1.76$ & $14 \pm 1.8$ & $14.1 \pm 1.74$ \\
\hline Platelets $\times 1000 / \mu \mathbf{L}$ & $120 \pm 60.9$ & $133 \pm 62.5$ & $115 \pm 59.6$ \\
\hline HCV RNA $\times 10^{6} \mathrm{IU} / \mathrm{mL}$ & $1.54 \pm 3.69$ & $1.46 \pm 1.92$ & $1.58 \pm 4.27$ \\
\hline
\end{tabular}

Abbreviations: ALT; alanine aminotransferase, BMI; body mass index, HCC; hepatocellular carcinoma, HCV RNA; hepatitis C virus-ribonucleic acid, SD; standard deviation. a Values are expressed as No. (\%) or mean + SD unless otherwise indicated.

containing group (7.2\% vs. $0.3 \%, \mathrm{P}<0.001)$, mainly due to RBV dose modification or RBV discontinuation. However, rate of treatment discontinuation was the same for both cohorts (3.8\% vs. 3.4\%). Adverse events were more frequently observed in RBV-containing regimens (43\% vs. $36.6 \%, \mathrm{P}=0.04$ ) with the most common weakness/fatigue reported in $18.5 \%$ of patients (Table 5). Rate of adverse events leading to treatment discontinuation was comparable in both cohorts. Serious adverse events were reported in $4.1 \%$ of patients, and tended to be more frequent in RBVfree cohort (4.9\% vs. 3.8\%), although not statistically significant, whereas the rate of liver-related events was the same for both populations.

Liver decompensation manifested as an ascites deterioration or hepatic encephalopathy was observed in $2.3 \%$ and $1.5 \%$ vs. $2.6 \%$ and $2.7 \%$ in RBV-free and RBV-containing groups, respectively (Table 5). A total of 16 deaths not related to treatment of $\mathrm{HCV}$ infection were documented, mostly in RBV-containing group.

\section{Discussion}

Patients with chronic HCV infection and liver cirrhosis are at the highest risk for liver-related complications. Numerous clinical trials and real-life studies have proved that HCV eradication in cirrhotic patients can reduce progress to end-stage liver disease, rate of hepatic decompensation, HCC development, need of transplantation, and mortality (11-14). In the interferon era, patients with HCV genotype 1 infection and liver cirrhosis have been recognized as difficult-to-treat due to low response rates and high frequency of side effects with consequent treatment discontinuation. Approval of the all-oral direct antiviral therapy resulted in significant improvement of treatment response and tolerability, even in cirrhotic patients (15-21). For that, in the beginning of the IFN-free era, antiviral treatment was prioritized in this population according to EASL and national guidelines $(8,9,22)$.

In the Polish real-world study we retrospectively evaluated the efficacy and safety of interferon-free regimens in this cohort. Since the beginning of the IFN-free era, the ad- 


\begin{tabular}{|c|c|c|c|c|}
\hline Parameter & All, $\mathbf{N}=1113$ & RBV-Free, $N=344$ & RBV-Containing $N=769$ & $\mathbf{P}^{\mathbf{b}}$ \\
\hline \multicolumn{5}{|l|}{ HCV genotype } \\
\hline 1 & $17(1.5)$ & $3(0.9)$ & $14(1.8)$ & 0.11 \\
\hline 1a & $21(1.9)$ & $3(0.9)$ & $18(2.4)$ & \\
\hline $1 \mathrm{~b}$ & $1075(96.6)$ & $338(98.2)$ & $737(95.8)$ & \\
\hline \multicolumn{5}{|l|}{ Liver fibrosis assessment } \\
\hline Biopsy & $155(13.9)$ & $30(8.7)$ & $125(16.2)$ & $<0.001$ \\
\hline TE & $814(73.1)$ & $256(74.4)$ & $558(72.6)$ & \\
\hline SWE & $141(12.7)$ & $58(16.9)$ & $83(10.8)$ & \\
\hline ARFI & $3(0.3)$ & 0 & $3(0.4)$ & \\
\hline \multicolumn{5}{|l|}{ History of hepatic decompensation } \\
\hline Ascites & $120(10.8)$ & $17(4.9)$ & $103(13.4)$ & 0.003 \\
\hline Encephalopathy & $32(2.8)$ & $6(1.7)$ & $26(3.4)$ & \\
\hline No data & $68(6.1)$ & $24(7)$ & $44(5.7)$ & \\
\hline Documented esophageal varices & $346(31.1)$ & $81(23.5)$ & $265(34.4)$ & $<0.001$ \\
\hline \multicolumn{5}{|l|}{ Hepatic decompensation at baseline } \\
\hline Moderate ascites-responded to diuretics & $44(3.9)$ & $7(2)$ & $37(4.8)$ & 0.41 \\
\hline Tense ascites-not responded to diuretics & $2(0.2)$ & $1(0.3)$ & $1(0.1)$ & \\
\hline Encephalopathy & $28(2.5)$ & $4(1.2)$ & $24(3.1)$ & \\
\hline \multicolumn{5}{|l|}{ MELD } \\
\hline$<15$ & $992(89.1)$ & $296(86)$ & $696(90.5)$ & 0.14 \\
\hline $15-18$ & $43(3.9)$ & $17(4.9)$ & $26(3.4)$ & \\
\hline $19-20$ & $11(1)$ & $6(1.8)$ & $5(0.6)$ & \\
\hline$>20$ & $13(1.2)$ & $6(1.8)$ & $7(0.9)$ & \\
\hline No data & $54(4.8)$ & $19(5.5)$ & $35(4.6)$ & \\
\hline \multicolumn{5}{|l|}{ Child-Pugh } \\
\hline A & $965(86.7)$ & $303(88.1)$ & $662(86.1)$ & 0.56 \\
\hline B & $105(9.4)$ & $27(7.8)$ & $78(10.1)$ & \\
\hline $\mathrm{C}$ & $9(0.8)$ & $2(0.6)$ & $7(0.9)$ & \\
\hline No data & $34(3.1)$ & $12(3.5)$ & $22(2.9)$ & \\
\hline History of liver cancer (HCC) & $46(4.1)$ & $14(4.1)$ & $32(4.1)$ & 0.95 \\
\hline $\begin{array}{l}\text { Liver transplant before treatment No. (\%), time from OLT (mo), } \\
\text { mean } \pm S D(\min -\max )\end{array}$ & $21(1.9), 66.8 \pm 58.2 ; 5-168$ & $4(1.2), 46 \pm 65 ; 5-120$ & $17(2.2), 71 \pm 58 ; 8-168$ & 0.23 \\
\hline HIV coinfection & $7(0.6)$ & $2(0.6)$ & $5(0.6)$ & 0.89 \\
\hline \multicolumn{5}{|l|}{ HBV coinfection } \\
\hline $\operatorname{HBsAg}(+) \operatorname{HBV}$ DNA (+) & $8(0.7)$ & 0 & $8(1.05)$ & 0.38 \\
\hline $\operatorname{HBsAg}(+) \operatorname{HBV}$ DNA $(-)$ & $3(0.3)$ & $1(0.3)$ & $2(0.3)$ & \\
\hline HBsAg (-)/aHBctotal (+) & $129(11.6)$ & $43(12.5)$ & $86(11.2)$ & \\
\hline \multicolumn{5}{|l|}{ Extrahepatic manifestation } \\
\hline Cryoglobulinemia & $69(6.2)$ & $15(4.4)$ & $54(7)$ & 0.004 \\
\hline Thyroid abnormalities with antithyroid antibodies & $13(1.2)$ & $7(2)$ & $6(0.8)$ & \\
\hline Other & $11(1)$ & $7(2)$ & $4(0.52)$ & \\
\hline
\end{tabular}

Abbreviations: ARFI; acoustic radiation force impulse, aHBctotal; antibody to the hepatitis B core antigen, HBsAg; hepatitis B surface antigen, HBV; hepatitis B virus, HBV DNA; hepatitis B virus deoxyribonucleic acid, HCV; hepatitis C virus, HIV; human immunodeficiency virus, MELD; model of end-stage liver disease, OLT; orthotopic liver transplantation, SWE; shear wave elastography, TE; transient elastography.

${ }^{a}$ Values are expressed as No. (\%) or mean + SD unless otherwise indicated.

${ }^{\mathrm{b}}$ P-value between RBV-free and RBV-containing.

dition of RBV was recommended in cirrhotics for possible improvement of efficacy, special attention was given in our study to compare RBV-free and RBV-containing regimens. The majority of analyzed cohort was infected with GT 1b, which is the most common subtype in Poland, and $87 \%$ was diagnosed as compensated (3).

Regimens prescribed for compensated patients in our study were OBV/PTV/r + DSV + RBV for 12 or 24 weeks de- 


\begin{tabular}{|c|c|c|c|}
\hline Parameter & All & 12 wk & 24 wk \\
\hline Without ribavirin $^{a}$ & 344 & 243 & 101 \\
\hline $\mathrm{ASV}+\mathrm{DCV}$ & $42(12.2)$ & 0 & 42 \\
\hline LDV/SOF & $81(23.5)$ & 22 & 59 \\
\hline $\mathrm{OBV} / \mathrm{PTV} / \mathrm{r}+\mathrm{DSV}$ & $218(63.4)$ & $218^{\mathrm{b}}$ & 0 \\
\hline $\mathrm{SOF}+\mathrm{SMV}$ & $3(0.9)$ & 3 & 0 \\
\hline With ribavirin $^{a}$ & 769 & 728 & 41 \\
\hline $\mathrm{SOF}+\mathrm{SMV}+\mathrm{RBV}$ & $2(0.3)$ & 2 & 0 \\
\hline $\mathrm{LDV} / \mathrm{SOF}+\mathrm{RBV}$ & $269(35)$ & 228 & 41 \\
\hline $\mathrm{OBV} / \mathrm{PTV} / \mathrm{r}+\mathrm{DSV}+\mathrm{RBV}$ & $498(64.7)$ & 498 & 0 \\
\hline
\end{tabular}

Abbreviations: ASV; asunaprevir, DCV; daclatasvir, DSV; dasabuvir, LDV; ledipasvir, OBV; ombitasvir, PTV; paritaprevir, r; ritonavir, RBV; ribavirin, SMV; simeprevir, SOF; sofosbuvir.

${ }^{\text {a }}$ Values represented as No. (\%).

${ }^{\mathrm{b}}$ Including one patient treated for 8 weeks.

\begin{tabular}{|c|c|c|c|c|}
\hline Regimen & All & RBV-Free & $\begin{array}{c}\text { RBV- } \\
\text { Containing }\end{array}$ & P-Value \\
\hline $\begin{array}{l}\text { OBV/PTV/r + } \\
\text { DSV, 12 } \\
\text { weeks }\end{array}$ & $\begin{array}{c}686 / 716 \\
(95.8)\end{array}$ & $\begin{array}{c}209 / 218 \\
(95.9)\end{array}$ & $\begin{array}{c}477 / 498 \\
(95.8)\end{array}$ & 0.95 \\
\hline $\begin{array}{l}\text { LDV/SOF, } 12 \\
\text { weeks }\end{array}$ & $\begin{array}{c}234 / 250 \\
(93.6)\end{array}$ & $22 / 22(100)$ & 212/228 (93) & 0.29 \\
\hline $\begin{array}{l}\text { LDV/SOF, } 24 \\
\text { weeks }\end{array}$ & $94 / 100(94)$ & $55 / 59$ (93.2) & 39/41(95.1) & 0.69 \\
\hline $\begin{array}{l}\text { SOF + SMV, } \\
12 \text { weeks }\end{array}$ & $5 / 5(100)$ & $3 / 3(100)$ & $2 / 2(100)$ & - \\
\hline $\begin{array}{l}\text { ASV }+ \text { DCV, } \\
24 \text { weeks }\end{array}$ & $35 / 42(83.3)$ & $35 / 42(83.3)$ & - & - \\
\hline $\begin{array}{l}\text { All } \\
\text { regimens }\end{array}$ & $\begin{array}{c}1054 / 1113 \\
(94.7)\end{array}$ & $\begin{array}{c}324 / 344 \\
(94.2)\end{array}$ & $\begin{array}{c}730 / 769 \\
(94.9)\end{array}$ & 0.61 \\
\hline $\begin{array}{l}12 \text { weeks } \\
\text { regimens }\end{array}$ & 925/971 (95.3) & $\begin{array}{c}234 / 243 \\
(96.3)\end{array}$ & $\begin{array}{c}691 / 728 \\
(94.9)\end{array}$ & 0.38 \\
\hline $\begin{array}{l}24 \text { weeks } \\
\text { regimens }\end{array}$ & $129 / 142(90.8)$ & $90 / 101(89.1)$ & $41 / 43(95.3)$ & 0.23 \\
\hline
\end{tabular}

Abbreviations: ASV; asunaprevir, DCV; daclatasvir, DSV; dasabuvir, LDV; ledipasvir, OBV; ombitasvir, PTV; paritaprevir, r; ritonavir, RBV; ribavirin, SMV; simeprevir, SOF; sofosbuvir.

a ITT - "intent to treat" analysis, which included all patients receiving at least 1 dose of the treatment.

${ }^{\mathrm{b}}$ Statistical significance of $\mathrm{P}<0.05$ between IFN-free vs IFN-containing regimens.

pending on GT1 subtype, combination of SOF/LDV + RBV for 12 weeks, simeprevir (SMV) and SOF with RBV for 12 weeks, and SOF plus daclatasvir (DCV) with RBV for 12 weeks. In Poland an additional regimen dedicated for GT $1 \mathrm{~b}$ patients - combination of DCV and asunaprevir (ASV) for 24 weeks was available (22). The choice for patients with decompensated cirrhosis (Child-Pugh B and Child-Pugh C) included the fixed-dose combination of SOF and LDV or SOF and DCV regimen with or without RBV, for 12 or 24 weeks, respectively. The first IFN-free regimen available in our country was OBV/PTV/r + DSV and almost two thirds of the study cohort was assigned to this therapeutic option, which was highly effective and safe in the real world experience (23, 24). Finally, $30 \%$ of cirrhotics were assigned to RBV-free regimens, of whom $70 \%$ were treated for 12 weeks. Over half of the entire study cohort was treatment experienced with higher percentage in RBV-containing group (59\% vs. $48 \%$ ); the majority of patients were previously treated with PegIFN and RBV, however, nearly $30 \%$ of them received triple therapy with the first generation protease inhibitors. As shown by our analysis IFN-free regimens were applied to more than 1100 cirrhotic patients with GT 1 infection. SVR rate in this historically defined "hard-to-treat" population reached 95\% and was similar in patients treated with both RBV-free and RBV-containing regimens. Twelve-week options without RBV were even more effective than 24 week ones (96\% vs. $89 \%$ ). This can be explained by fact that $42 \%$ of patients in 24 -wks population was treated with DCV and ASV with SVR of $83 \%$. A similar outcome was reported for cirrhotics in the HALLMARK-DUAL study, therefore, this regimen was finally recognized as a suboptimal therapeutic option (25). High response rates for other IFN-free regimens, with and without ribavirin, observed in the current analysis, are comparable to clinical trial results. Two phase 3 randomized studies with SOF/LDV \pm RBV for 12 or 24 weeks (ION-1 and ION-2) reported SVR rate of $82 \%-100 \%$ in cirrhotics, according to the previous treatment history with no effect of RBV addition $(26,27)$. Patients infected with GT1b with compensated liver cirrhosis treated with OBV/PTV/r + DSV for 12 weeks in the TURQUOISE-III study achieved SVR of 100\% (19). Excellent efficacy demonstrated in the current analysis is highly consistent with recently published real-world European studies, which evaluated IFN-free options applied to GT 1 infected cirrhotics and demonstrated no difference between RBV-free and RBVcontaining cohorts (28-39). There are some indications supporting more frequent use of ribavirin in patients with more advanced liver disease, which could theoreticaly affect our efficacy analysis. According to data presented in Table 2 the only significant difference was related to historic information on possible worse hepatic conditions in the RBV group (history of decompensation and oesophageal varices). However, it was not a case for current hepatic compensation status (signs of hepatic decompensation, MELD, Chil-Pugh, HCC and liver transplantation) at the begining of the treatment.

The tolerability profile of IFN-free regimens in the current analysis was in accordance with clinical trials and realworld studies (40-45). A total of $41 \%$ of the entire cohort reported at least one AE, more often in RBV-containing group. 


\begin{tabular}{|c|c|c|c|c|}
\hline Parameter & All N = 1113 & RBV- $\mathbf{N}=\mathbf{3 4 4}$ & $\mathbf{R B V}+\mathbf{N}=769$ & P-Value \\
\hline Patients with at least one $\mathrm{AE}$ & $457(41.1)$ & $126(36.6)$ & $331(43)$ & 0.04 \\
\hline Serious adverse events & $46(4.1)$ & $17(4.9)$ & $29(3.8)$ & 0.36 \\
\hline SAEs liver-related ${ }^{a}$ & $18(1.6)$ & $6(1.7)$ & $12(1.6)$ & 0.82 \\
\hline \multicolumn{5}{|l|}{ Most common AEs (> 5\%) } \\
\hline Weakness/fatigue & $206(18.5)$ & $57(16.6)$ & $149(19.4)$ & 0.26 \\
\hline Anemia & $56(5.1)$ & $5(1.5)$ & $55(7.2)$ & $<0.001$ \\
\hline Pruritus & $62(5.6)$ & $20(5.8)$ & $42(5.5)$ & 0.81 \\
\hline \multicolumn{5}{|l|}{ AEs of particular interest } \\
\hline Deterioration of ascites & $28(2.5)$ & $8(2.3)$ & $20(2.6)$ & 0.78 \\
\hline Hepatic encephalopathy & $26(2.4)$ & $5(1.5)$ & $21(2.7)$ & 0.20 \\
\hline Gastrointestinal bleeding & $9(0.8)$ & $2(0.6)$ & $7(0.9)$ & 0.32 \\
\hline Death $^{b}$ & $16(1.4)$ & $2(0.6)$ & $14(1.8)$ & 0.11 \\
\hline
\end{tabular}

Abbreviations: AE; adverse event, CCC; cholangiocarcinoma, HCC; hepatocellular carcinoma, SAE; serious adverse event.

${ }^{a}$ RBV-free group: HCC 3 patients, hepatic decompensation, increase of bilirubin level, increase of ALT activity; RBV-containing group: HCC 5 patients, hepatic decompensation 3 patients, portal vein thrombosis 2 patients, dysplastic nodules, CCC.

${ }^{\mathrm{b}}$ HCC 4 patients, decompensation 3 patients, pancreatic cancer 2 patients, sudden cardiac death 2 patients, cholangiocarcinoma, acute pancreatitis, subarachnoid hemorrhage, intra-peritoneal bleeding, unknown reason (death in follow-up).

The most common AEs were weakness/fatigue, pruritus, and in individuals treated with RBV, anemia. The majority of patients completed the treatment course as scheduled with a low rate of discontinuations. Therapy modification concerned only RBV-containing options and included RBV dose reduction or discontinuation due to anemia.

The overall rate of serious adverse events was low (4\%), and there were no significant differences between groups. Detailed analysis revealed that liver-related events rate was the same for both cohorts. No adverse events related to drug-drug interactions were observed. Deaths reported in the study, mostly in RBV-containing arm, were considered by investigators as not related to treatment.

Limitations of this study included it's retrospective observational nature resulting in underreporting of minor adverse events, electronic data collection connected with potential physician bias, choice of the regimen and treatment duration based on investigator discretion meaning no randomization, as well as possible data entry errors. Duration of follow up period seems to be insufficient to assess the benefits of successful treatment in terms of reducing disease progression.

Strengths of our study are large number of patients from numerous hepatologic centers, resulting with diversity of patient population managed in routine practice, and low rate of patients lost to follow-up (2\%).

\subsection{Conclusions}

In summary, we confirmed high effectiveness and safety of the interferon and ribavirin-free regimens in realworld setting of cirrhotics with chronic genotype $1 \mathrm{HCV}$ infection.

\section{References}

1. Xu F, Moorman AC, Tong X, Gordon SC, Rupp LB, Lu M, et al. All-Cause Mortality and Progression Risks to Hepatic Decompensation and Hepatocellular Carcinoma in Patients Infected With Hepatitis C Virus. Clin Infect Dis. 2016;62(3):289-97. doi: 10.1093/cid/civ860. [PubMed: 26417034].

2. The Polaris Observatory HCV Collaborators. Global prevalence and genotype distribution of hepatitis C virus infection in 2015: a modelling study. Lancet Gastroenterol Hepatol. 2017;2(3):161-76. doi: 10.1016/S2468-1253(16)30181-9. [PubMed: 28404132].

3. Flisiak R, Pogorzelska J, Berak H, Horban A, Orlowska I, Simon K, et al. Prevalence of HCV genotypes in Poland - the EpiTer study. Clin Exp Hepatol. 2016;2(4):144-8. doi: 10.5114/ceh.2016.63871. [PubMed: 28856279]. [PubMed Central: PMC5497426].

4. Bota S, Sporea I, Popescu A, Sirli R, Neghina AM, Danila M, et al. Response to standard of care antiviral treatment in patients with HCV liver cirrhosis-a systematic review. J Gastrointestin Liver Dis. 2011;20(3):293-8.

5. Bota S, Sporea I, Sirli R, Popescu A, Neghina AM, Danila M, et al. Severe adverse events during antiviral therapy in hepatitis $C$ virus cirrhotic patients: A systematic review. World J Hepatol. 2013;5(3):1206. doi: 10.4254/wjh.v5.i3.120. [PubMed: 23556044]. [PubMed Central: PMC3612570].

6. Somasundaram A, Venkataraman J. Antiviral treatment for cirrhosis due to hepatitis C: a review. Singapore Med J.2012;53(4):231-5. [PubMed: 22511042]. 
7. Silva GF, Villela-Nogueira CA, Mello CE, Soares EC, Coelho HS, Ferreira $\mathrm{PR}$, et al. Peginterferon plus ribavirin and sustained virological response rate in HCV-related advanced fibrosis: a real life study. Braz J Infect Dis. 2014;18(1):48-52. doi: 10.1016/j.bjid.2013.05.007. [PubMed: 24055310].

8. Pawlotsky JM, Aghemo A, Back D, Dusheiko G, Forns X, Puoti M, et al. EASL recommendations on treatment of hepatitis C 2015. J hepatol. 2015;63(1):199-236.

9. European Association for The Study of The Liver. EASL recommendations on treatment of hepatitis C 2016. J hepatol. 2017;66(1):153.

10. European Association for the Study of the Liver. EASL-ALEH Clinical Practice Guidelines: Non-invasive tests for evaluation of liver disease severity and prognosis. J hepatol. 2015;63(1):237-64.

11. Backus LI, Belperio PS, Shahoumian TA, Mole LA. Impact of sustained virologic response with direct-acting antiviral treatment on mortality in patients with advanced liver disease. Hepatology. 2018. doi: 10.1002/hep.29408.

12. Kutala BK, Guedj J, Asselah T, Boyer N, Mouri F, Martinot-Peignoux $\mathrm{M}$, et al. Impact of treatment against hepatitis $\mathrm{C}$ virus on overall survival of naive patients with advanced liver disease. Antimicrob Agents Chemother. 2015;59(2):803-10. doi: 10.1128/AAC.04027-14. [PubMed: 25403673]. [PubMed Central: PMC4335837].

13. Iacobellis A, Ippolito A, Andriulli A. Antiviral therapy in hepatitis C virus cirrhotic patients in compensated and decompensated condition. World J Gastroenterol. 2008;14(42):6467-72.

14. Bruno S, Stroffolini T, Colombo M, Bollani S, Benvegnu L, Mazzella $\mathrm{G}$, et al. Sustained virological response to interferon-alpha is associated with improved outcome in HCV-related cirrhosis: a retrospective study. Hepatology. 2007;45(3):579-87. doi: 10.1002/hep.21492. [PubMed: 17326216].

15. Charlton M, Everson GT, Flamm SL, Kumar P, Landis C, Brown RS, et al. Ledipasvir and Sofosbuvir Plus Ribavirin for Treatment of HCV Infection in Patients With Advanced Liver Disease. Gastroenterology. 2015;149(3):649-59. doi: 10.1053/j.gastro.2015.05.010. [PubMed: 25985734].

16. Young J, Weis N, Hofer H, Irving W, Weiland O, Giostra E, et al. The effectiveness of daclatasvir based therapy in European patients with chronic hepatitis $\mathrm{C}$ and advanced liver disease. BMC Infect Dis. 2017;17(1):45. doi: 10.1186/s12879-016-2106-x. [PubMed: 28061762]. [PubMed Central: PMC5219681].

17. Manns M, Samuel D, Gane EJ, Mutimer D, McCaughan G, Buti M, et al. Ledipasvir and sofosbuvir plus ribavirin in patients with genotype 1 or 4 hepatitis $C$ virus infection and advanced liver disease: a multicentre, open-label, randomised, phase 2 trial. Lancet Infect Dis. 2016;16(6):685-97. doi: 10.1016/S1473-3099(16)00052-9. [PubMed: 26907736].

18. Poordad F, Hezode C, Trinh R, Kowdley KV, Zeuzem S, Agarwal K, et al. ABT-450/r-ombitasvir and dasabuvir with ribavirin for hepatitis C with cirrhosis. N Engl J Med. 2014;370(21):1973-82. doi: 10.1056/NEJMoa1402869. [PubMed: 24725237].

19. Feld JJ, Moreno C, Trinh R, Tam E, Bourgeois S, Horsmans Y, et al. Sustained virologic response of $100 \%$ in HCV genotype $1 \mathrm{~b}$ patients with cirrhosis receiving ombitasvir/paritaprevir/r and dasabuvir for 12weeks. J Hepatol. 2016;64(2):301-7. doi: 10.1016/j.jhep.2015.10.005 [PubMed: 26476290].

20. Lawitz E, Makara M, Akarca US, Thuluvath PJ, Preotescu LL, Varunok P, et al. Efficacy and Safety of Ombitasvir, Paritaprevir, and Ritonavir in an Open-Label Study of Patients With Genotype 1b Chronic Hepatitis C Virus Infection With and Without Cirrhosis. Gastroenterology. 2015;149(4):971-80 e1. doi: 10.1053/j.gastro.2015.07.001. [PubMed: 26170136].

21. Lawitz E, Matusow G, DeJesus E, Yoshida EM, Felizarta F, Ghalib R, et al. Simeprevir plus sofosbuvir in patients with chronic hepatitis $C$ virus genotype 1 infection and cirrhosis: A phase 3 study (OPTIMIST2). Hepatology. 2016;64(2):360-9. doi: 10.1002/hep.28422. [PubMed: 26704148]. [PubMed Central: PMC5297873].
22. Halota W, Flisiak R, Boron-Kaczmarska A, Juszczyk J, Malkowski P, et al. Recommendations for the treatment of hepatitis $\mathrm{C}$ issued by the Polish Group of HCV Experts - 2016. Clin Exp Hepatol. 2016;2(2):27-33. doi: 10.5114/ceh.2016.59099. [PubMed: 28856269]. [PubMed Central: PMC5497405].

23. Flisiak R, Flisiak-Jackiewicz M. Ombitasvir and paritaprevir boosted with ritonavir and combined with dasabuvir for chronic hepatitis C. Expert Rev Gastroenterol Hepatol. 2017;11(6):559-67. doi: 10.1080/17474124.2017.1309284. [PubMed: 28317409].

24. Flisiak R, Janczewska E, Wawrzynowicz-Syczewska M, Jaroszewicz J, Zarebska-Michaluk D, Nazzal K, et al. Real-world effectiveness and safety of ombitasvir/paritaprevir/ritonavir +/- dasabuvir +/- ribavirin in hepatitis C: AMBER study. Aliment Pharmacol Ther. 2016;44(9):94656. doi: 10.1111/apt.13790. [PubMed: 27611776].

25. Manns M, Pol S, Jacobson IM, Marcellin P, Gordon SC, Peng CY, et al. All-oral daclatasvir plus asunaprevir for hepatitis $\mathrm{C}$ virus genotype 1b: a multinational, phase 3, multicohort study. Lancet. 2014;384(9954):1597-605. doi: 10.1016/S0140-6736(14)61059-X. [PubMed: 25078304].

26. Afdhal N, Zeuzem S, Kwo P, Chojkier M, Gitlin N, Puoti M, et al. Ledipasvir and sofosbuvir for untreated HCV genotype 1 infection. $N$ Engl J Med. 2014;370(20):1889-98. doi: 10.1056/NEJMoa1402454. [PubMed: 24725239].

27. Afdhal N, Reddy KR, Nelson DR, Lawitz E, Gordon SC, Schiff E, et al. Ledipasvir and sofosbuvir for previously treated HCV genotype 1 infection. NEngl J Med. 2014;370(16):1483-93.

28. Barone M, Iannone A, Shahini E, Ippolito AM, Brancaccio G, Morisco F, et al. A different perspective on sofosbuvir-ledipasvir treatment of patients with HCV genotype 1b cirrhosis: The ital-c network study. $J$ Viral Hepat. 2018;25(1):56-62. doi: 10.1111/jvh.12765. [PubMed: 28787102].

29. Marino Z, Pascasio-Acevedo JM, Gallego A, Diago M, Baliellas C, Morillas R, et al. High efficacy of Sofosbuvir plus Simeprevir in a large cohort of Spanish cirrhotic patients infected with genotypes 1 and 4 . Liver Int. 2017;37(12):1823-32. doi: 10.1111/liv.13470. [PubMed: 28481460].

30. Preda CM, Popescu CP, Baicus C, Voiosu TA, Manuc M, Pop CS, et al. Real-world efficacy and safety of ombitasvir, paritaprevir/r+dasabuvir+ribavirin in genotype $1 \mathrm{~b}$ patients with hepatitis C virus cirrhosis. Liver Int. 2018;38(4):602-10. doi: 10.1111/liv.13550. [PubMed: 28816020].

31. Hezode C. Treatment of hepatitis C: Results in real life. Liver Int. 2018;38:21-7.

32. Lai JB, Witt MA, Pauly MP, Ready J, Allerton M, Seo S, et al. Eight-or 12week treatment of hepatitis $C$ with ledipasvir/sofosbuvir: real-world experience in a large integrated health system. Drugs. 2017;77(3):313-8.

33. Louie V, Latt NL, Gharibian D, Sahota A, Yanny BT, Mittal R, et al. RealWorld Experiences With a Direct-Acting Antiviral Agent for Patients With Hepatitis C Virus Infection. Perm J. 2017;21. doi: 10.7812/TPP/16096. [PubMed: 28368787]. [PubMed Central: PMC5378486].

34. Backus LI, Belperio PS, Shahoumian TA, Loomis TP, Mole LA. Realworld effectiveness and predictors of sustained virological response with all-oral therapy in 21,242 hepatitis C genotype-1 patients. Antivir Ther. 2017;22(6):481-93. doi:10.3851/IMP3117. [PubMed: 27934775].

35. Bachofner J, Valli PV, Bergamin I, Kroger A, Kunzler P, Baserga A, et al. Excellent outcome of direct antiviral treatment for chronic hepatitis C in Switzerland. Swiss Med Wkly. 2018;148:w14560. doi: 10.4414/smw.2018.14560. [PubMed: 29376557].

36. Chamorro-de-Vega E, Gimenez-Manzorro A, Rodriguez-Gonzalez CG, Escudero-Vilaplana V, De Lorenzo-Pinto A, Iglesias-Peinado I, et al. Twelve weeks of ombitasvir/paritaprevir/ $\mathrm{r}$ and dasabuvir without ribavirin is effective and safe in the treatment of patients with HCV genotype $1 \mathrm{~b}$ infection and compensated cirrhosis: results from a real-world cohort study. Expert Opin Drug Saf. 2018;17(3):235-41. doi: 10.1080/14740338.2018.1424829. [PubMed: 29325476].

37. Calleja JL, Crespo J, Rincon D, Ruiz-Antoran B, Fernandez I, Perello C, et al. Effectiveness, safety and clinical outcomes of direct-acting 
antiviral therapy in HCV genotype 1 infection: Results from a Spanish real-world cohort. J Hepatol. 2017;66(6):1138-48. doi: 10.1016/j.jhep.2017.01.028. [PubMed: 28189751].

38. Chang CY, Nguyen P, Le A, Zhao C, Ahmed A, Daugherty T, et al. Real-world experience with interferon-free, direct acting antiviral therapies in Asian Americans with chronic hepatitis $\mathrm{C}$ and advanced liver disease. Medicine (Baltimore). 2017;96(6). e6128. doi: 10.1097/MD.0000000000006128. [PubMed: 28178174]. [PubMed Central: PMC5313031]

39. Fox DS, McGinnis JE, Tonnu-Mihara IQ, McCombs JS. Comparative treatment effectiveness of direct acting antiviral regimens for hepatitis C: Data from the Veterans administration.J Gastroenterol Hepatol. 2017;32(6):1136-42. doi: 10.1111/jgh.13652. [PubMed: 27869323].

40. Reddy KR, Bourliere M, Sulkowski M, Omata M, Zeuzem S, Feld JJ, et al. Ledipasvir and sofosbuvir in patients with genotype 1 hepatitis $C$ virus infection and compensated cirrhosis: An integrated safety and efficacy analysis. Hepatology. 2015;62(1):79-86. doi: 10.1002/hep.27826. [PubMed: 25846144].

41. Ahmed H, Abushouk AI, Menshawy A, Mohamed A, Negida A, Loutfy SA, et al. Safety and Efficacy of Ombitasvir/Paritaprevir/Ritonavir and Dasabuvir with or without Ribavirin for Treatment of Hepatitis C Virus Genotype 1: A Systematic Review and Meta-analysis. Clin Drug Investig. 2017;37(11):1009-23. doi: 10.1007/s40261-017-0565-5. [PubMed: 28871475].
42. Ioannou GN, Beste LA, Chang MF, Green PK, Lowy E, Tsui JI, et al. Effectiveness of sofosbuvir, ledipasvir/sofosbuvir, or paritaprevir/ritonavir/ombitasvir and dasabuvir regimens for treatment of patients with hepatitis $C$ in the Veterans Affairs National Health Care System. Gastroenterology. 2016;151(3):457-471. e5.

43. Bourliere M, Bronowicki JP, De Ledinghen V, Hezode C, Zoulim F, Mathurin $\mathrm{P}$, et al. Ledipasvir-sofosbuvir with or without ribavirin to treat patients with HCV genotype 1 infection and cirrhosis nonresponsive to previous protease-inhibitor therapy: a randomised, double-blind, phase 2 trial (SIRIUS). Lancet infect dis. 2015;15(4):397404.

44. Trifan A, Stanciu C, Gheorghe L, Iacob S, Curescu M, Cijevschi Prelipcean C, et al. Efficacy and safety of paritaprevir/ritonavir, ombitasvir, and dasabuvir with ribavirin for the treatment of HCV genotype $1 \mathrm{~b}$ compensated cirrhosis in patients aged 70 years or older. Medicine (Baltimore). 2017;96(50). e9271. doi 10.1097/MD.0000000000009271. [PubMed: 29390377]. [PubMed Central: PMC5815789].

45. Welzel TM, Hinrichsen H, Sarrazin C, Buggisch P, Baumgarten A, Christensen S, et al. Real-world experience with the all-oral, interferon-free regimen of ombitasvir/paritaprevir/ritonavir and dasabuvir for the treatment of chronic hepatitis C virus infection in the German Hepatitis C Registry. J Viral Hepat. 2017;24(10):840-9. doi: 10.1111/jvh.12708. [PubMed: 28342229]. 